\title{
داعش : حقيقة التنظيم والأهداف
}

\author{
هنادي عبد الغني فضل السيد \\ باحثة في مركز دراسات الشرق الاوسط وافريقيا- الخرطوم السودان \\ e-mail: hanadi_fadbl@gmail.com
}

DOI: http:/ / dx.doi.org/10.30983/islam_realitas.v2i1.128

\begin{tabular}{l|l|l} 
Diterima: 23 Maret 2016 & Direvisi : 2 April 2016 & Diterbitkan: 20 Juni 2016
\end{tabular}

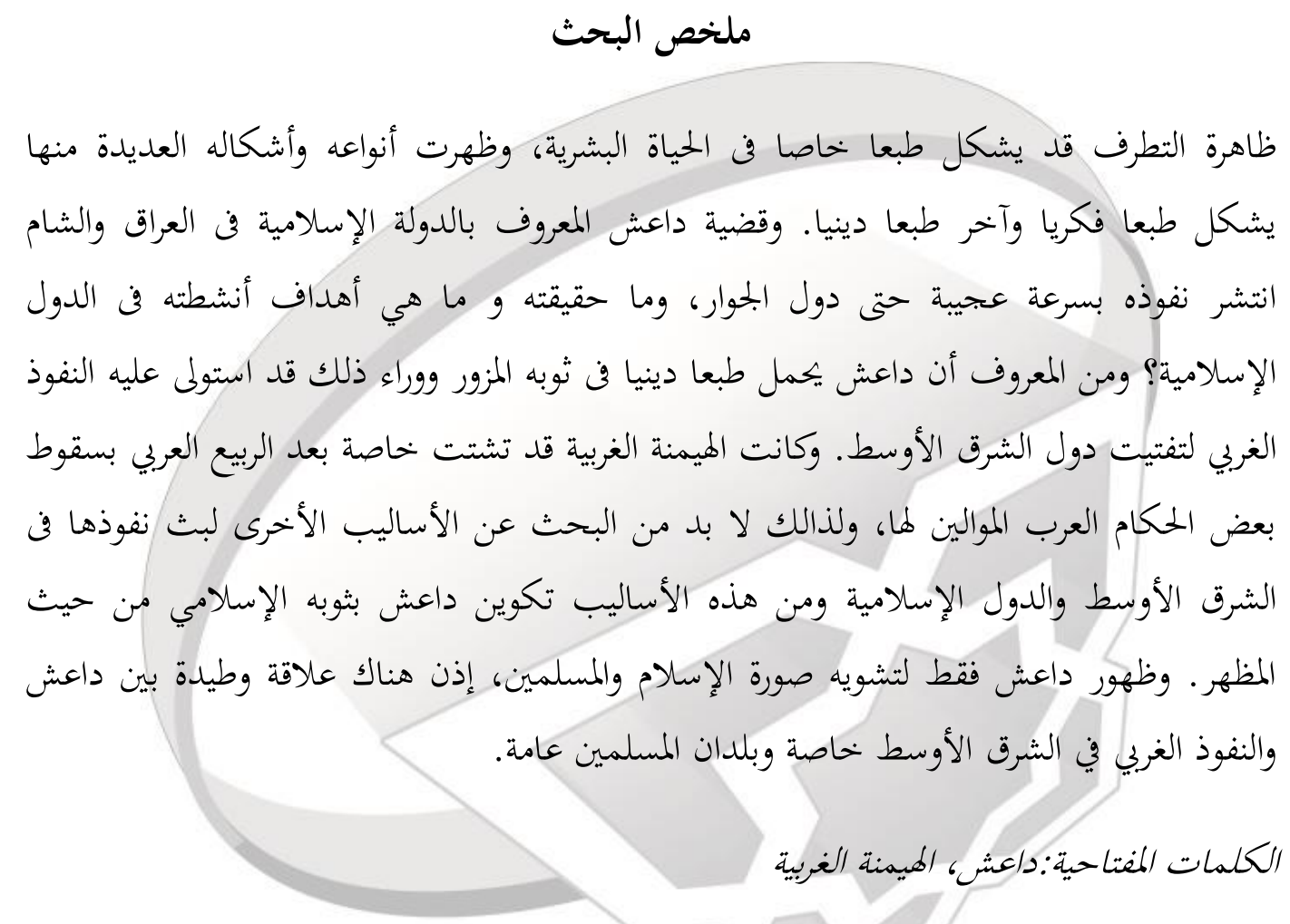

Abstrak

Fenomena kekerasan dalam berbagai aktifitas manusia sudah jadi warna tersendiri. Berbagai corak kekerasan muncul dalam berbagai bentuk dan warna. Salah satu bentuknya adalah bercorak dan bertameng agama, di antaranya adalah fenomena ISIS. Bagaimana akhirat dan tujuan gerakannya?. Terkesan corak aktifitas mereka bercorak keagamaan, tapi dibalik itu ada agenda pesanan Barat yang untuk memecah belahTimur Tengah. Hegemoni Barat yang mulai terancam setelah munculnya musim semi negera-negara Arab dengan bertumbangnya para penguasa diktator. Perlu ada skenario baru buat menguatkan tancapan pengaruh Barat di Timur Tengah dengan melahirkan ISIS. Keberadaan ISIS memang dimunculkan by design yang rapi antara kekuatan yang berpengaruh di kancah percaturan politik dunia. Jadi ISIS hanya memperburuk citra Islam yang bermula di Iraq dan Suria dan melebar ke berbagai penjuru dunia. Jadi ISIS dan hegemoni Barat punya keterkaitan erat dalam mencaplok Timut Tengah secara khusus dan dunia Islam secara umum.

Kata Kunci: Kekerasan Bahasa, Solusi 
لتوظيفه القرآن الكريم، والسنة النبوية في

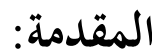
تمدد تنظيم داعش في العديد من البلدان تبريراته وفتواه، والأهم صدام هذا الخطاب وانتشر كالنار في الهشيم بداية من العراق العقائدي مع الأنظمة الحاكمة، وظهوره

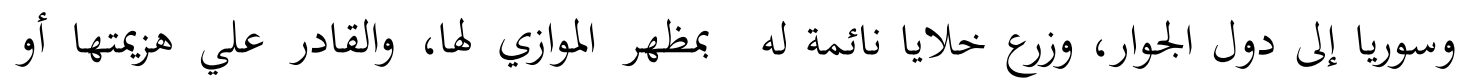

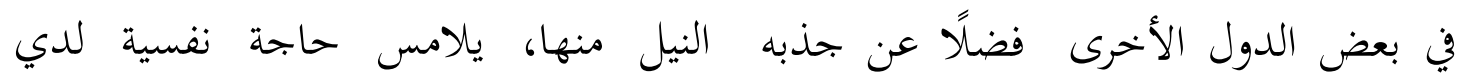

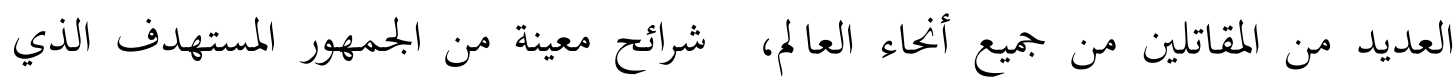
تمكن تنظيم الدولة الإسلامية "داعش " يعاني غضبا وتمميشا وفراغا ناجما عن الشعور وبعد أن كان وجوده يقتصر في أطراف بعض بانكسار الذات الناشئ عن الصعوبات البلدان أصبح الآن في أعماق العالم لمعيشية، أو عدم القدرة علي التوفيق بين

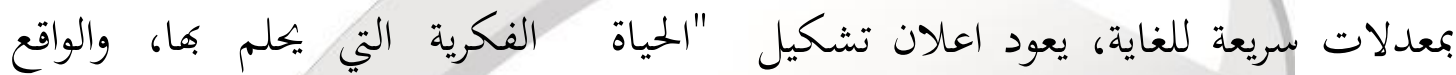

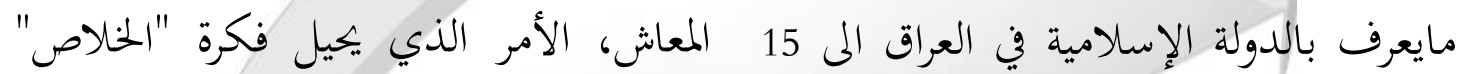

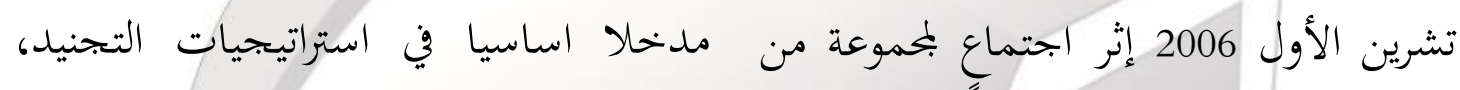
الفصائل المسلحة في العراق، وأختير حينها و والتأطير، والاستقطاب من من قبل الجماعات

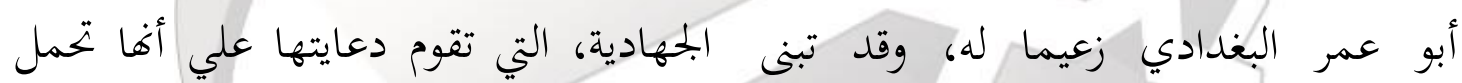

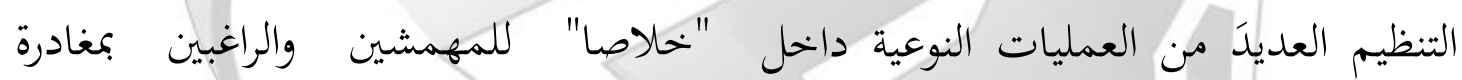

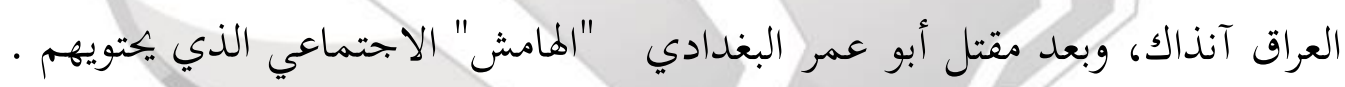

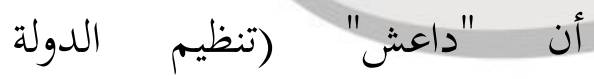
في 2010/4/19، أصبح "أبو بكر البغدادي" ابو عدر البعدي" الإسلامية) يخوض اليوم حربا حقيقية لتشويه

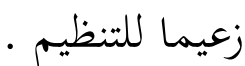

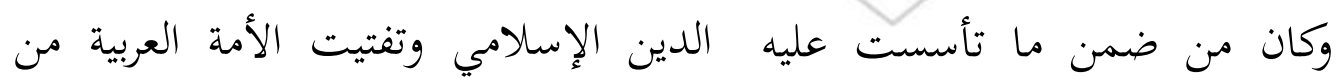
خطابات الحركات السلفية الجهادية أها الداخل، وأن الجرائم المتعاقبة التي يقترفها

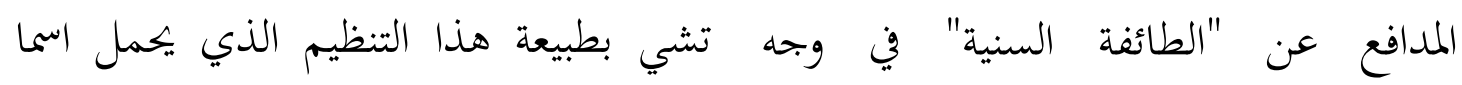
الطوائف الأخرى، خصوصا حين تتوافر علي إسلاميا ظاهرا، وصناعة غربية-إسرائيلية

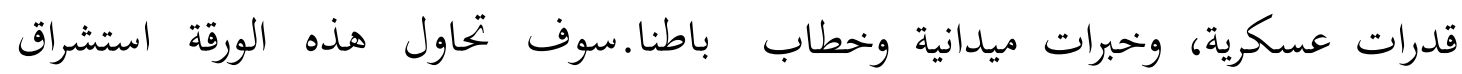
عقائدي مبسط ومختصر، يبدو معهودا مستقبل تنظيم الدولة الاسلامية المعروف وتربه 
صفوفها. أما من ناحية داعش فهي تعتمد بشكل كبير على العنصر الأجنبي المقاتل الذي يغلب عددياً على العنصر السوري ان لندير

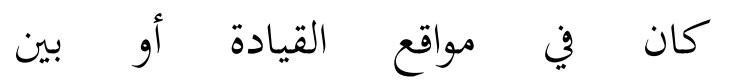
المقاتلين(1).تشكّل تنظيم "الدولة الاسلامية

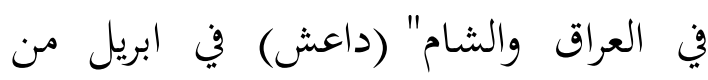

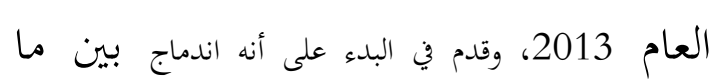
يسمى بـ "دولة العراق الإسلامية" التابع لتنظيم "القاعدة" الذي تشكّل في أكتوبر الإسل 2006 وبين المحموعة الإسلامية المسلحة في

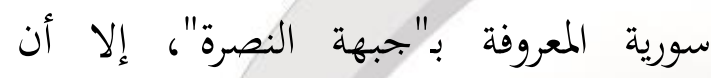

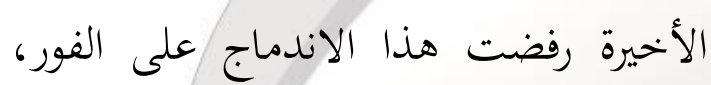

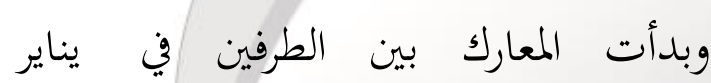

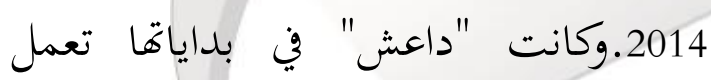
تحت أسم "جماعة التوحيد والجهاد" بزعامة ابي مصعب الزرقاوي في عام 2004، قبل أن

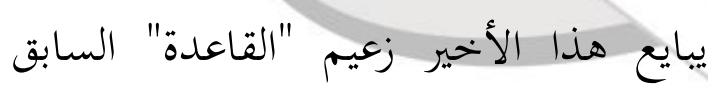
اسامة بن لادن ليصبح اسمه "القاعدة في

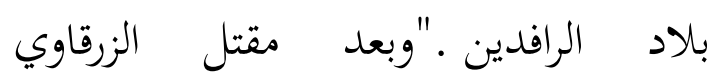
"انتخب" ابي حمزة المهاجر زعيما للتنظيم. وبعد أشهر أعلن عن تشكيل "دولة العراق الاسلامية" بزعامة ابي عمر البغدادي. كانت القوات الأمريكية بنحت في (ابريل) 2010

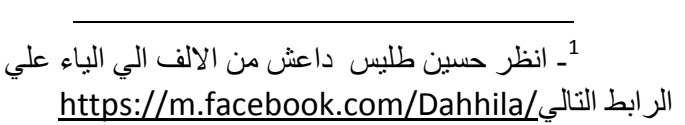

بداعش وهل يمكن ان ينتشر ويستمر في العديد من البلاد ام اها سوف تخبو وتنجلي

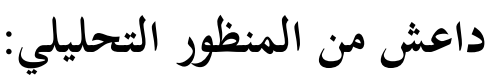
يجمل كل من النصرة وداعش، فكراً

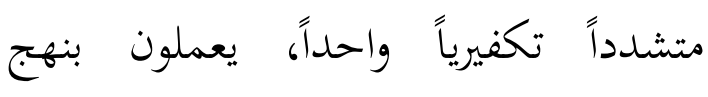
السلفية الجهادية، و مؤمنان بقيام الدولة الإسلامية في الشام، إلا أن الفرق بين التنظيمين يكمن في قربهم من الواقع السوري

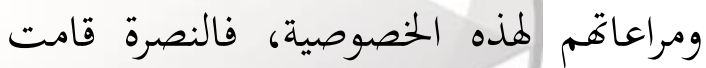

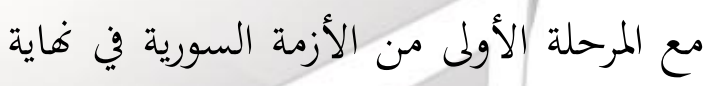
العام 2011، واكتسبت خبرة و دراية بواقع البختمع السوري، تأسست النصرة من زعماء سوريين بينهم من كان معتقلا في السجون

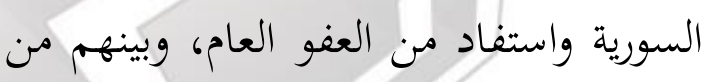
كان يمارس الدعوة سرياً في سوريا قبيل اندلاع الأزمة، وآخرين كانوا منضوين تحت لواء القاعدة و قاتلوا في بلدان أخرى كالعراق و أفغانستان و الشيشان وعادوا مع بداية الأزمة في سوريا للقتال فيها كما هو حال أمير جبهة النصرة ابو محمد الفاتح "الجولاني" لهوريا لهونال

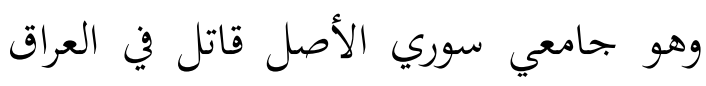

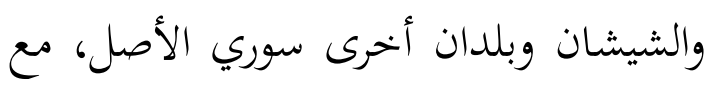
وجود عدد لا بأس به من الأجانب في الاصني سعري 
المعارضة السورية المسلحة المقاتلة في ريف دير الزور، الى مبايعة "الدولة الاسلامية" او

$$
\text { الانسحاب من مواقعها (4). }
$$

كل هذه المؤشرات والمعلومات تؤكد ما بات معروفا في وسائل الإعلام من أن سوريا والعراق أصبحا بيئتين جاذبتين للجهاديين والإرهابيين من جنسيات عربية، وإسلامية، وأجنبية وافدة ومتسللة. وهذا الأمر لا يقتصر في الحقيقة، علي الجانب

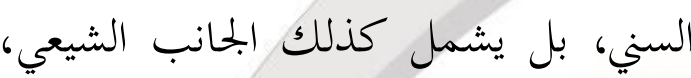
حيث المشاركة في الحرب في سوريا لا تقتصر علي "حزب الله" اللبناني، ولواء "أبو الفضل

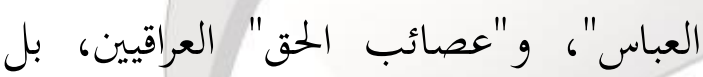
تتعداهم إلى كويتيين وأفغان وسواهم.وفق ولق بعض التقديرات الأولية- تبدو كافية لتحريك عدد من مواطني الدول الخليجية من

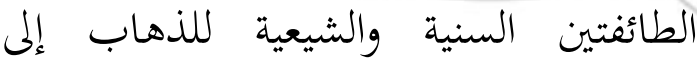
العراق، تحت شعار الدفاع عن المقدسات الدينية، وهو أمر ليس بجديد على دول الخليج. فقد برزت خلال الفترة الأخيرة،

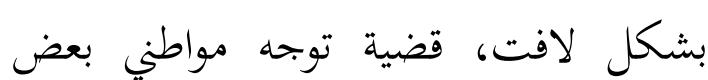

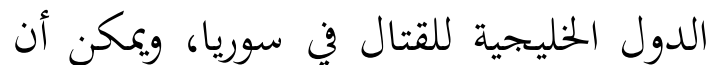

الكانـانظر القسس العربي تنظين الدولة الاسلامية يرغم آلف السكان على مغادرة بلداتهم شرق سوريا علي الر ابط التالي لئي http://www.alquds.co.uk/?p=189404
في قتل البغدادي ومساعده ابي حمزة المهاجر، فاختار التنظم ابا بكر البغدادي خليفة له

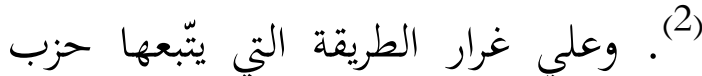
الله، وعلى عكس الطرق التي ت تتبعها بحموعات إسلامية جهادية أخرى في سورية، لايلتط تنظيم داعش عادةً صوراً لقادته أو

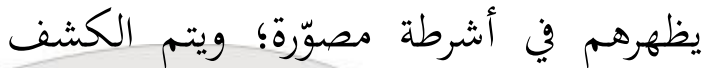
عن معظم أسمائهم وصورهم فقط في حال مصرعهم (وطيلة بقائهم على قيد الحياة، تحمل كل الأخبار التي تُنشَر عنهم أسماء

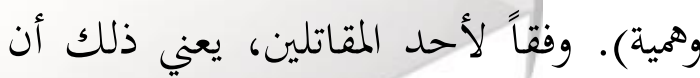
قادة التنظيم الذين قُتلوا لحلال حملة التحالف الدولي لم يكونوا بمغظمهم من القادة الرئيسين، ذلك أن هؤلاء غلن غالباً مايعملون في السر ويبقون بجهولي الهوية(3) تمكن تنظيم "اللدولة الاسلامية" الذي بات فيعول يسيطر على مساحات شاسعة في شثمال

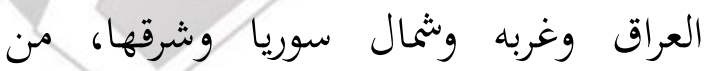
الاستيلاء على قرى ومدن عدة في دير الزور من دون مقاومة تذكر، اذ دفع الخوف تهن ونقص السلاح والتجهيزات، فصائل

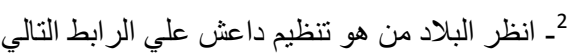

http://www.elbilad.net/flash/detail?id=13052

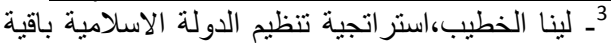
وتتتمديبتاريخ 29 يونيو علي رابط مركز كارينغي للشرق

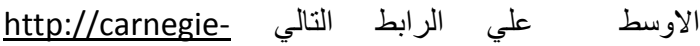
mec.org/publications/?fa=60542 
يتكرر ذلك الآن مع العراق، لتتكرر أيضاً الممتدة وجذب تلك الأعداد من المقاتلين

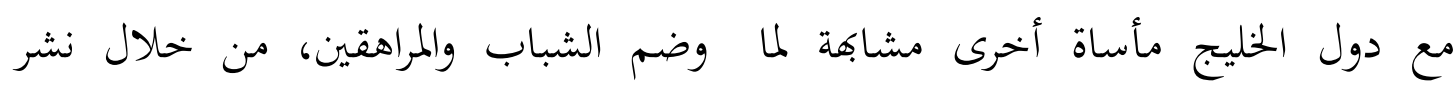
حدث بعد احتلال العراق في مارس 2003، الانتصارات التي حققها ونشر الأفكار التي وما سمي فيما بعد بـ "العائدين من العراق"، تتعلق بنيل الشهادة وبث صورة جذابة

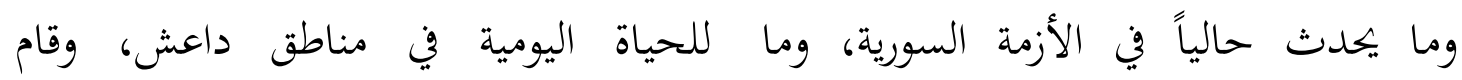
يسمى أيضاً بـ "العائدين من سوريا". التنظيم بنشر المادة الإعلامية بلغات مختلفة فتقديرات وزارة الداخلية السعودية، على فلم تقتصر فقط على اللغة العربية والانحليزية

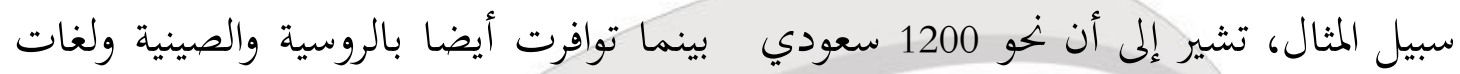

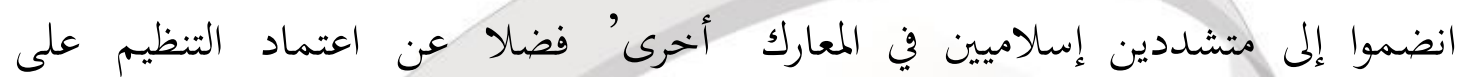
الدائرة في سوريا، من ضمن نحو 11 ألف تطبيقات "سكاى بى وواتس أب" من أجل إل

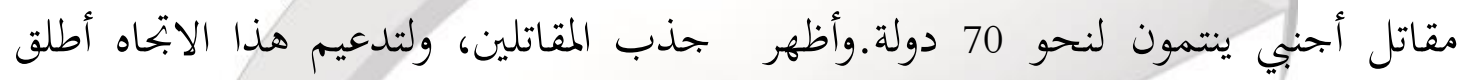

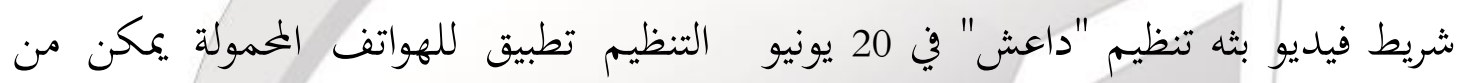
2014 خمسة مقاتلين إسلاميين متشددين خلالها متابعة أخبار التنظيم (5).

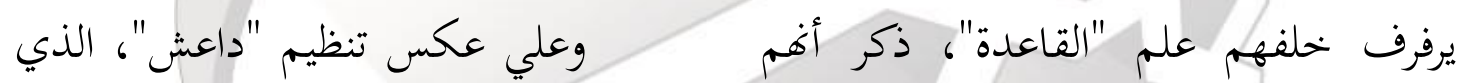
يحملون الجنسيتين البريطانية والأسترالية، دعوا يعد تنظيما عابرا للدول ويضم في صفوفه

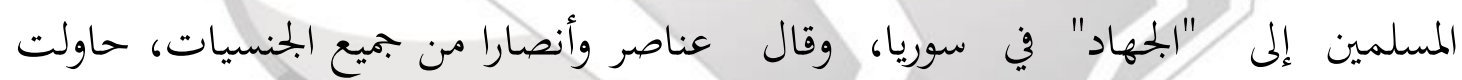
أحدهم باللغة الإبحليزية: "نحن دولة تطبق "جبهة النصرة" التي تعتبر الفرع السوري

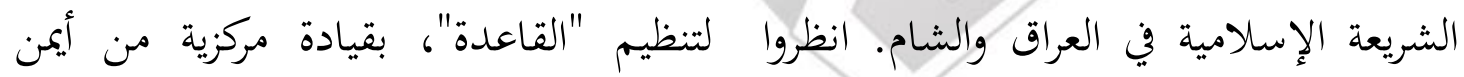

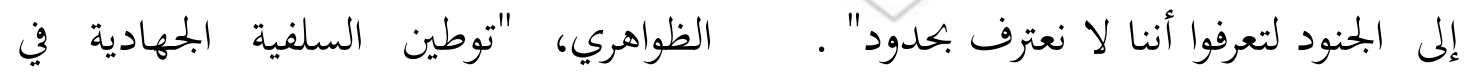

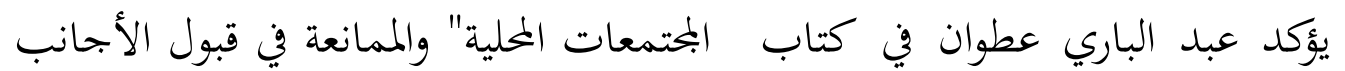
"الدولة الإسلامية. الخلافة الرقمية"'انه في صفوفها. كما عرف عن تنظيم "أحرار وبدون التكنولوجيا الرقمية كان من المستحيل الشام"، وهو فصيل عسكري جهادي ناشط

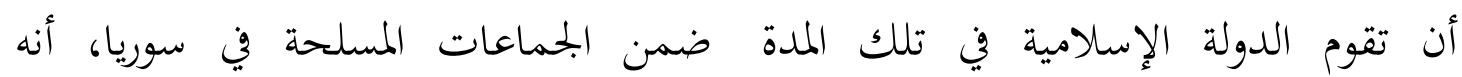

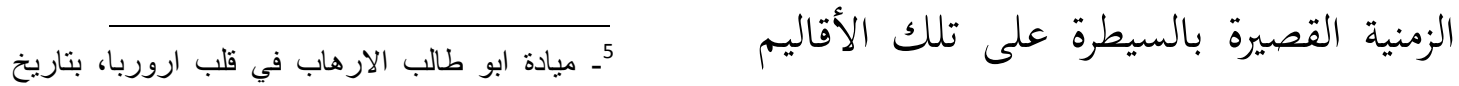

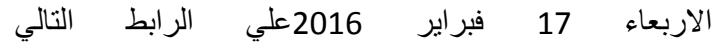
http://www.elmogaz.com/node/267811 
استخدم داعش ترويج الإيديولوجيا

يحاول، برغم اعتماده فكر "القاعدة"، أن

يتجنب فكرة "الجهاد العالمي"، ويؤشر جنباً إلى جنب مع الاستراتيجية العسكرية

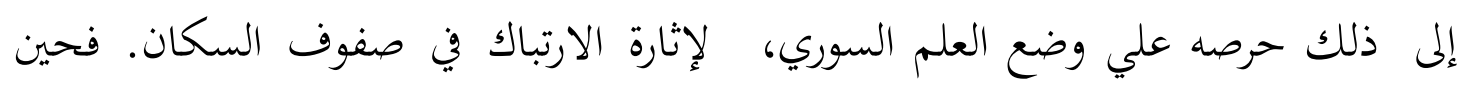

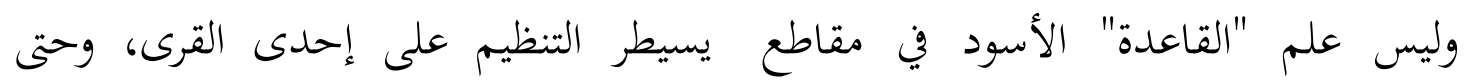

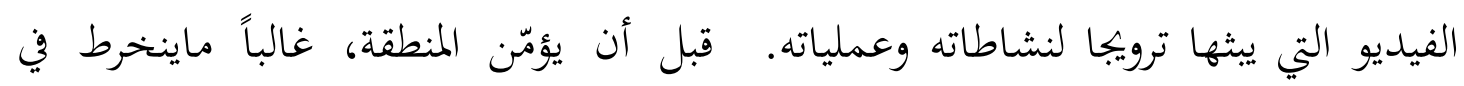

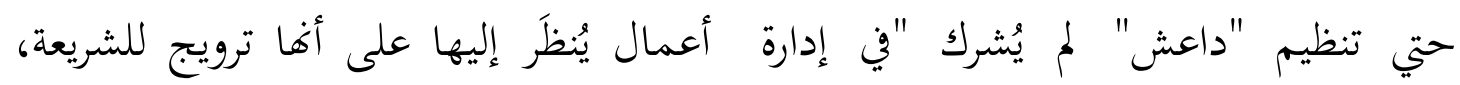

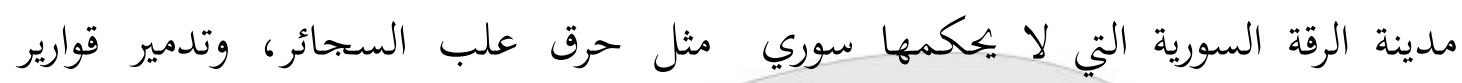

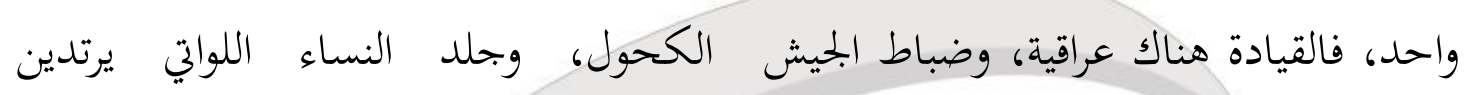

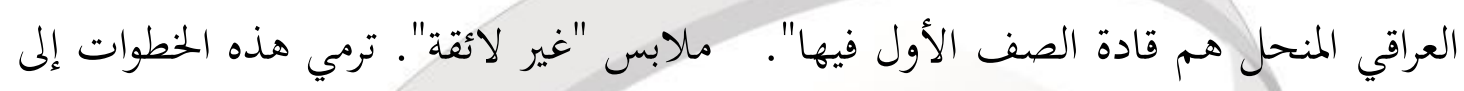

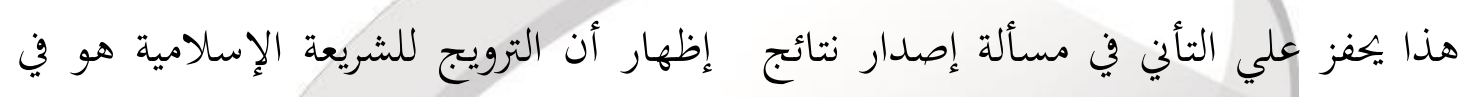
هائية في مسألة الأصيل، والوارد فيما خص ملب صلب أولويات التنظيم، مايساعده على نيل

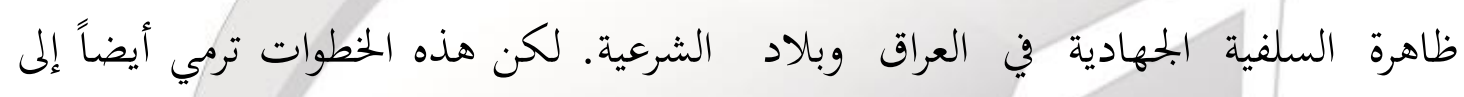

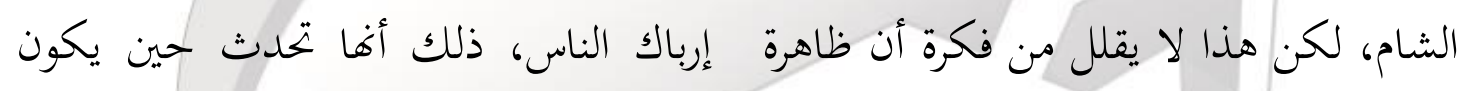

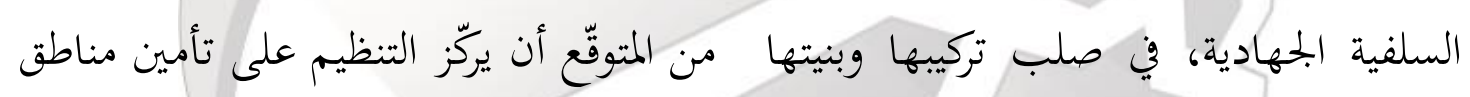
الفكرية والتنظيمية والتمويلية، هي ظاهرة استولى عليها حديثاً (7).

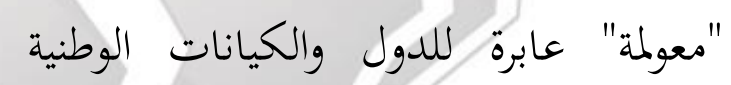

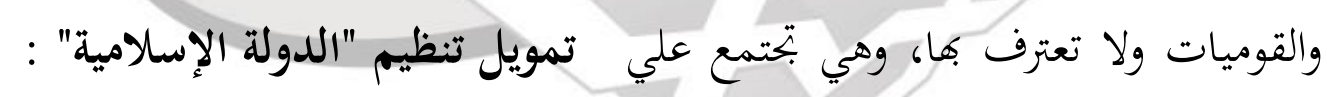

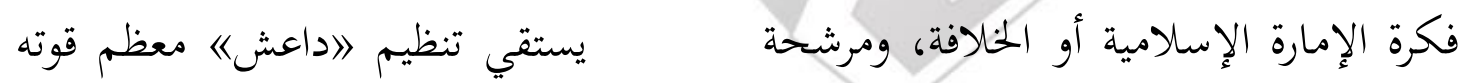

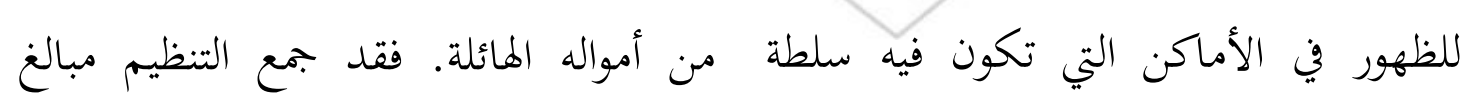
الدولة واهنة، وتعاني فراغا سياسيا، وتسود طائلة من الأموال من خلال نظول نظام تمويل

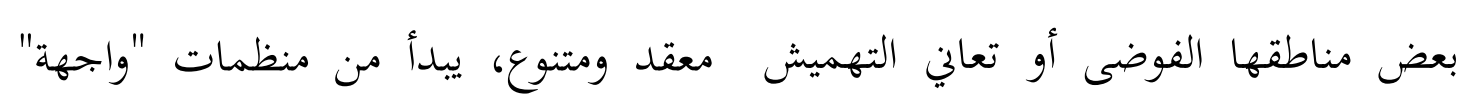
والإقصاء والتمييز، خاصة إذا كان علي تعمل تحت غطاء مؤسسات خهات خيرية ليصل إلى عمليات بيع النفط في السوق السوداء

خلفيات طائفية، ومذهبية. (6) والأصيز،

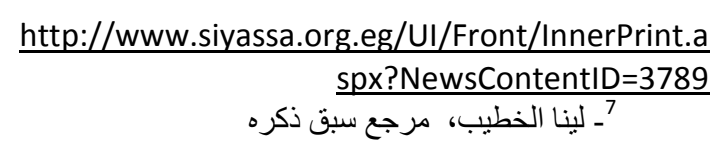
داعش: حقيقة التنظبيم ة/ألهد/ف

6ــــانظر السياسة الدولية، القابلية للاحتضان:عوامل

صعود السلية الجهادية في بلاد الثنام، علي الرابط التالي هنادى عبد الغني فضل السبي 


\section{مخطط تقسيم الشرق الأوسط :}

من ضمن المخطط القذر الذي

وضعه اليهودي (برنارد لويس) سنة 1980 بناء

على طلب وزير الدفاع الأمريكي حيث قسم

لويس المنطقة العربية ورسم لها خارطة

جديدة بدلا من سايكس - بيكو لتكون

خارطة أمريكية جديدة للمنطقة العربية..

فقد قدم لويس المخطط الجحديد إلى

الكوبحرس الأمريكي فوافق عليه بالإجماع

ووضع في ملف السياسة الخارجية الأمريكية

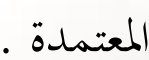

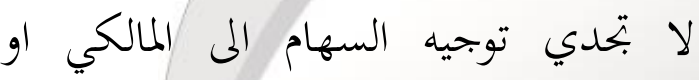

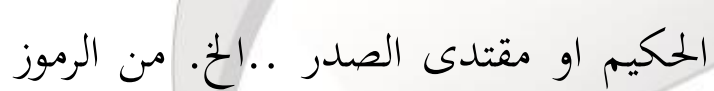

الطائفية التي عملت على المحاصصة ولم تعمل

على خلق دولة واحدة قوية مثلما كان

العراق ـ فالعراق سوف يقسم الى3 دول. .

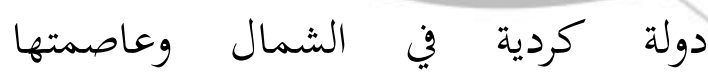

اربيل,ودولة للشيعة في الجنوب وعاصمتها

البصرة، ودولة للمسلمين السنة في الوسط

وعاصمتها بغداد. اي ان قوات داعش ودول

السنية سوف تحتل بغداد بحسب التقسيم

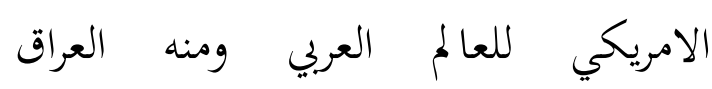

العظيم. فهجوم (داعش) يتم بمباركة

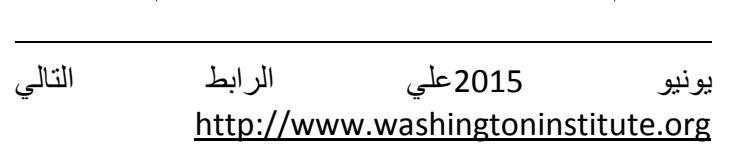

داعش: حقبقة التنظبيمة ة/لأ هداف

وفرض ضرائب على سائقي الثاحنات المحليين وأصحاب الأعمال وموظفي الحكومة ورتئ

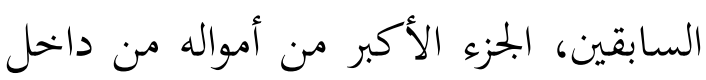

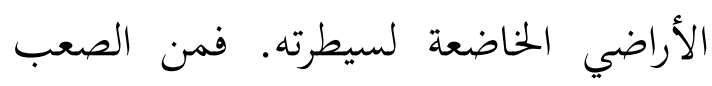
استهاف العائدات من الأراضي المحلية عن طريق أنشطة متنوعة مثل الابتزاز والجريمة و "فرض ضرائب" على السكان المحليين، وبطبيعة الحال، بيع النفط والقطع الأثرية - فرصني بعقوبات أكثر بكثير من الإيرادات الأخرى.

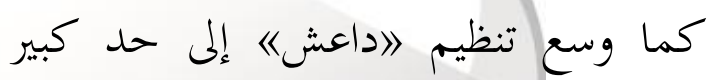
قاعدة إيراد|ته، عبر "استيلائه على أراضي في لئ

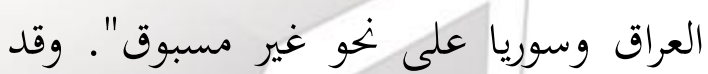
حقق أعظم مكسب مفاجئ له على الأرجح من خلال استيلائه على الموصل في يونيو

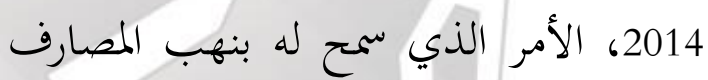
بحرية وفرض ضرائب على العمليات التجارية وابتزاز السكان. وفي حين من المستحيل معرفة الأرقام الدقيقة، تقدّر وزارة الخارجية الأمريكية أن "تنظيم 》الدولة الإسلامية/ قد الد حصل ما يصل إلى عدة ملايين من الدولارات شهرياً بواسطة شبكات الابتزاز المتنوعة والنشاط الإجرامي في الأراضي التي نشط فيها (8).

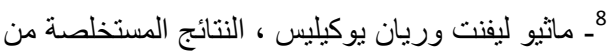
تصليل وزارة الخارجية الامريكية عن الارهاب الجزء الثانياني

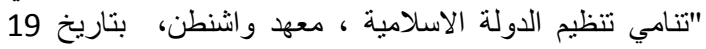


أمريكية..والأقمار الصناعية الأمريكية تصور الفلسطينيين في قطاع غزة وهم تحت أنفاس المهاجمين ولم تتكلم (9)، تنبع أهمية الحصار، داعش تنظيم يستغل اسم الإسلام

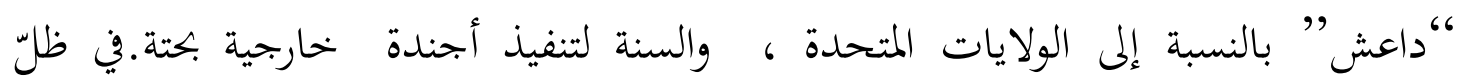
من حيث أها تضرب عدة عصافير بحجر اعتقاد جازمًا بأنه من غير الممكن أن يظهر إنها

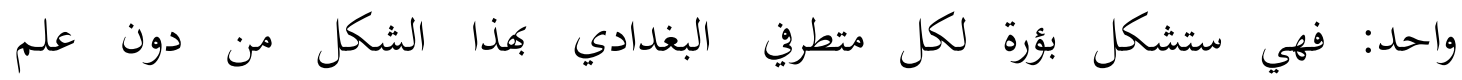
الخطاب الإسلاموي مما يسهل حصرهم في المخابرات الأميركية التي تتحكم بكلّ شاردة

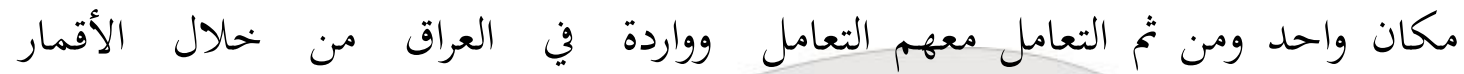

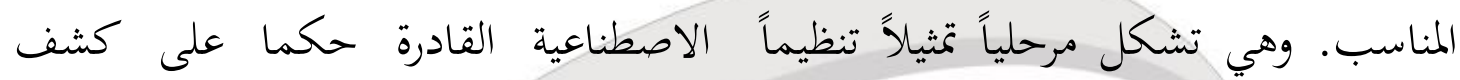
لسنة وعشائر العراق والشام، وبعد استيفاء المستور، خصوصًا أنّ البغدادي أخذذ وقته الغرض منها، أي من منظمة داعش، يسهل كاملا للخروج من مقره ومن ثم التوجه إلى ولى

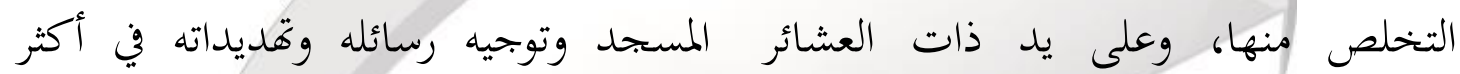
والطائفة السنية، ولا عزاء للمغسولة أدمغتهم من ابتحاه، ما يعني تكرارًا لمشهد سيطرة

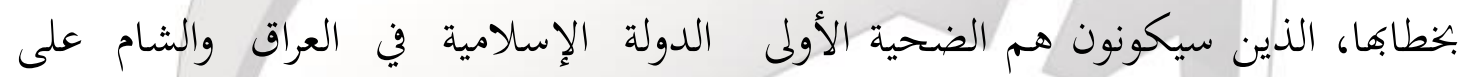
والأخيرة لمثل هذه اللعبة السياسية(10).

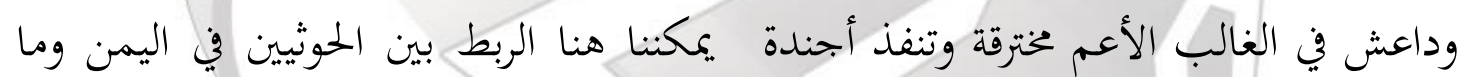
تصب في صالح الغرب بكل قوة، وتسعى الى يجري في العراق ومن المتمل ان سيطرة تقسيم منطقة الشرق الأوسط كما وضعه الحوثيين على معاقل المتشددين في عمران اليهودي (برنارد لويس)، فنجد ان المخطط تشكل بداية للتقدم باتجاه المحدود السعودية يسير في الاتحاه الذي رسم له بكل دقة وبند في ضغط إيراني جديد على السعودية علها ان إسرائيل استغلت هذه الأوضاع والفوضى تنتظم بالحرب على الإرهاب وتوقف تمويلها الخلاقة في المنطقة وأشعلتها حرب ضد للتنظيمات التكفيرية والوهابية والسلفية بجتمعة (12)وهذا ثاني احتمال لداعش بان ولئن

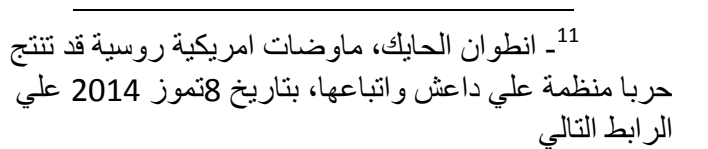
http://www.elnashra.com/news/show/765412 أنطوان الحايك مرجع سبق ذكرة

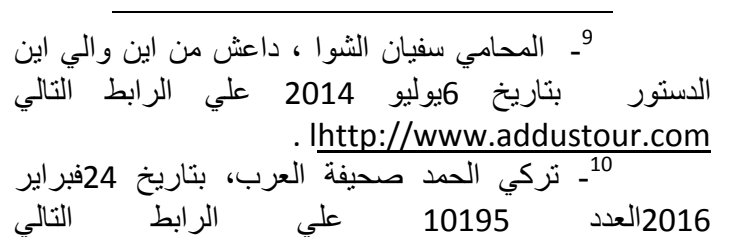
http://www.alarab.co.uk/?id=28390 
تكون السعودية ممول رئيسي لها والاحتمال الاسد.هذا وتسيطر الولايات المتحدة الأكبر هو الذي يتمثل في ان داعش في وداعش على بترول اربيل في العراق وتريد الأساس صنعه أمريكية لتمرير أجندة غربية الولايات المتحدة تقسيم العراق المى ثلاث لتقسم وتفكيك الشرق الأوسط وبحسب و ولايات سنية وشيعة واكراد (14). بعض الدعاة الإسلاميين منهم على سبيل وفي مقال للمحامي ناصر الدويلة عضو

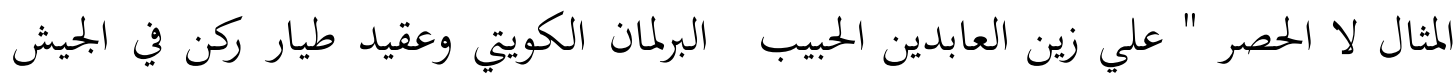

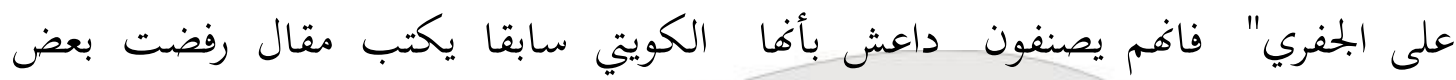
بحموعة إرهابية تقاتل باسم الإسلام وان الصحف العربية نشرها وتحفظت عليها وقد بإن الإسلام لمج يأمر بمثل هذه الأفعال التي ذكر ان المشروع الامريكي في العراق شيعي

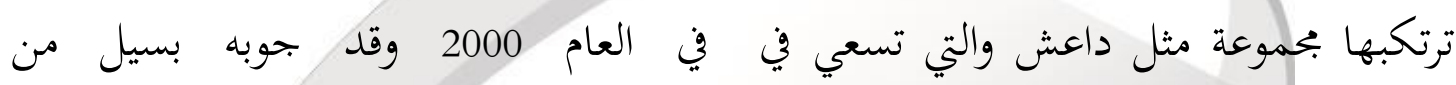

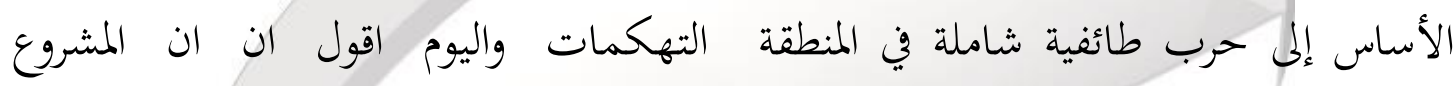
اذن لابد من التأني والحنر والنظر في مثل الامريكي الروسي الصيني الاوربي في الخليج هذه البمموعات التي تستغل اسم الدين شيعي ايضا وهذه مقدماته: اسقاط حكم مرسي لتنفيذ وتحقيق اغراضها (13) ابقاء حكم بشار الاسد وتدمير ومن ضمن التحليلات المذكورة عن داعش ونش السنة في سوريا

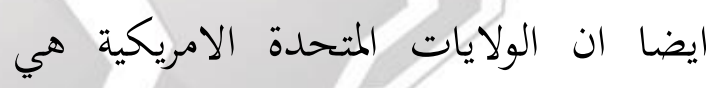
الممول الرئيس والصديق المقرب لداعش لاهنا اشغال تركيا وانتزاع الاغلبية من

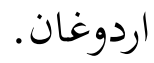

اشغال السعودية في اليمن واعتمادها المبالغ فيه على الدور الاماراتي اشغال قطر في المرحلة التالية تريد احتلال العراق وسلب بتروله ومعلوم ان العراق من أكبر الاقطار التي تتموي على البترول في العالم ينافسها في ذلك الاتحاد الاسوفيتي الذي يريد ايضا بترول العراق، يعمل الاتحاد السوفيتي في سوريا ويدعم لدئي

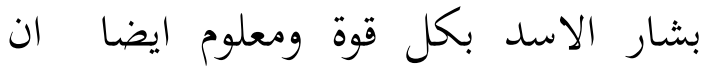
السوفيت والايرانيين هم اصدقاء لبشار 
حضور داعش في اليمن محدود مقارنة بحضور القاعدة في شبه الجزيرة العربية، الفرع الأقوى للتظيم الإرهابي. أما في أفغانستان وباكستان، أعلنت داعش في وقت سابق من العام الجاري تأسيس ولاية خراسان في منطقة تمتد على أجزاء من باكستان وأفغانستان وتشق طريقها نهو مناطق سيطرة طالبان، من خحلال مقاتلين أجانب يجندون مقاتلين محليين، وتبنى التنظيم أول هجوم كبير له في أفغانستان حين فجر انتحاري نفسه في جلال آباد موديا بعشرات الأرواح، أما طالبان فنشرت رسالة تحث التنظيم على البقاء خارج أفغانستان.كما وتشير الصحيفة إلى أنه في داغستان أعلن متمردون مقرهم شثمال القوقاز في روسيا ولائهم لداعش، وأعلنوا تأسيس ما يدعى ولاية داغستان، وكان المسلحون ينتمون إلى إمارة
المحافظة علي علي داعش قوية في كل مكان وهي راس الحربة الامريكية الفارسية (15). وكانت صحيفة الغاردين البريطانية قد نشرت محاولات تمدد داعش في بلاد العالم منها وعلي سبيل المثال لا الحصر تمدددها وانتشار في كل من مصر، ففي أعقاب ثورة 25 يناير التي أطاحت برئيس مصر الأسبق "حسني مبارك"ظهرت بحموعة تدعى “"ولاية سيناء ”عرفت سابقا بأنصار بيت المقدس وتصاعد عنف هجماتما بعد عزل الرئيس الإخوايي "“حمد مرسي" وبايعت البغدادي بالولاء في 2014 الماضي ك وذكرت الصحيفة أنه في اليمن، انتشرت سيارات مدمرة إثر تفجير في مسجد القبة الخضراء في 17 يونيو في هجوم تبنته داعش، موضحة أن

$$
\text { 15.ـــــليل ناصر الدويلة عضو البرلمان الكويني انظر }
$$

موقع بـtps://ar ar.facebook.com/MntdyAlatsamAldwy/posts/91 $\underline{0389982382603}$ 
بدأت داعش مؤخرا بمحاولات

لتجنيد مقاتلين من بين الفقراء

والشباب العاطلين عن العمل في

البلقان، مركزة على البوسنة والهرسك

كل هذه محاولات من داعش

للانتشار والتمدد في العالم منها تركيا

واندونسيا ايضا وستحاول هذه

الدراسة رصد دراسة ماولاتما

الاخيرة في الهجوم علي اندونسيا في

محاولة منها لمد اذرعها في العالم

محاولة انتشار داعش في ل

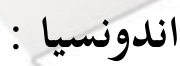

كانت أستراليا حذّرت من

أن تنظيم 》داعش《 يعزز وجوده في

إندونيسيا من أجل إقامة الخلافة

بعيدة) في هذه الدولة التي تضم

أكبر عدد من المسلمين في العالم،

موضحة أن ذلك يشكّل تمديداً

لأستراليا والمصالح الغربية. كما ذكر

16 الجرديان تنثر خريطة انتثار داعش من سوريا

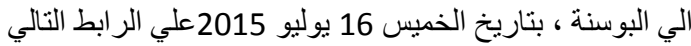

http://elbadil.com/2015/07/16
القوقاز، وهي جماعة إرهابية تبنت

عدة تفجيرات في موسكو. وفي

ليبيا ظهرت جماعة أنصار الشريعة،

إحدى أكبر المليشيات بالبلاد

والمتهمة بقتل السفير الأمريكي

بطرابلس عام 2012، أعلنت

نفسها من جديد على أها داعش

في بنغازي وصبراته وسرت. وفي

تونس، قتل سائحتان بريطانية

وإيرلندية، ويعتبر المقاتلون التونسيون

الحزان الأكبر للمقاتلين الأجانب في

داعش . أما غرب إفريقيا، ففي

مارس أعلنت جماعة بوكو حرام

مبايعتها لداعش، التي رحبت بذلك

سعيا لنشر خلافتها المعلنة ذاتيا في

غرب أفريقيا، وجماعة بوكو حرام التي

تأسست مطلع القرن فرضت الشريعة

شمال نيجيريا، وذبحت الآلاف،

وارتكبت مئات عمليات الخطف في

سياق هجمات امتدت إلى الجارتين

تشاد والنيجر. اما البوسنة، فقد 
أفادت وكالات الأنباء باحتجاز 4

أشخاص في المحافظة بنفس التهمة

في وقت سابق.وأشارت المصادر إلى أن الشرطة صادرت أثناء احتجازها

المتهمين متفجرات يدوية الصنع وأسلحة نارية وذخائر. يذكر أن

الشرطة الإندونيسية بتري عمليات

تمدف إلى اعتقال قائد تنظيم إرهابي

يسمى "سانتوزو"، يتكون من 31

شخصًا كان قد قد أعلن الولاء

ل"داعش." ومعلوم ان التنظيم

》داعش《 الإرهابي ضرب قلب

العاصمة الإندونيسية جاكارتا بتاريخ

14يناير 2016 ل حيث هاجم

انتحاريون تابعون له بالمتفجرات

والرصاص ، ما أدى إلى مقتل

مدنيين أحدهما غربي ومقتل خمسة

مهاجمين(18) هذا ويعتقد مسؤولون

في جهات مكافحة الإرهاب أنه

18

2016/01/15

http://www.alkhaleej.ae/alkhaleej/page/076581d8

-6b5f-44f9-b3b9-e38b9fecc351
النائب العام الأسترالي جورج

برانديس الذي عقد لقاءات مع

وزراء إندونيسيين بحضور أعضاء في

الحكومة الاسترالية، وقادة الشرطة

ومسئولي الامن لصحيفة اذي

استراليان《 ان 》اتنظيم داعش لديه

طموحات بتعزيز وجوده وحجم

نشاطه في إندونيسيا بشكل مباشر

أو و وكلا.

وأضاف «هل سمعتم بعبارة خلافة

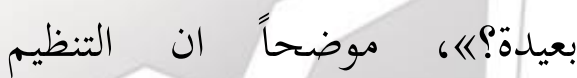

المتشلد 》اعلن نيته اقامة مناطق

خلافة خارج الشرق الاوسط، في

الواقع ولايات تابعة للخلافة وحدد

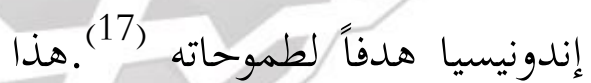

وقد جرت عملية تفتيش أجرتيت

في محافظة سيلاوسي الوسطى 3

واعتقال أشخاص يشتبه في

انتمائهم لتنظيم "داعش . ."كما

2017 انظر الموقعى الثالي بناريخ الثلاثاء، 22 ديسمبر

2015

http://s.youm7.com/2504902

http://www.youm7.com/s 
الإرهاب. هذا وقد تمكنت إندونيسيا

من حماية نفسها من أعمال العنف

العام الماضي بسبب عدم مهارة

المهاجمين ويقظة الشرطة، وكان

بحموع القتلى في عام 2015 ثمانية،

وفي عام 2014 كان العدد أربعة،

وكان تفجير يوم الخميس الأكثر

فتكاً بالنظر إلى أن منفذيه كانوا

مدربين (20). ويري بعض المحللين انه

ليس هناك دليل على أن منطقة

جنوب شرق آسيا تبرز بشكل

حقيقي وسط الحسابات

الاستراتيجية لقيادة التنظيم في الرقة.

يبرز المقاتلون المنحدرين من جنوب

شرق آسيا بكتيبة 》انوسانتارا|،، وهي

الوحدة التي تضم مقاتلي جنوب

شرق آسيا في سوريا، والتي تذكر

تقارير أن نعيم يقودها. وقد وجد

داعش في جنوب شرق آسيا

مناصرين له، ولكن القليل منهم

$$
\text { 20 انظر حسن عبده حسن عن نييورك تايمز }
$$

http://www.emaratalyoum.com/politics/reports -and-translation/2016-01-20-1.86122
يوجد 1000 متعاطف على الأقل مع

(19)

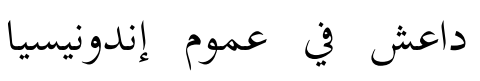

الهجوم الذي أدى اللى مقتل أربعة

مدنيين ومثلهم من الإرهابيين في

جاكرتا، ربما يعد مؤشراً إلى قدوم

العنف إلى هذا البلد ـ هذا ويشار

إلى أن تنظيم 》داعش《 الذي أعلن

مسؤوليته عن الهجوم، حول أعماله

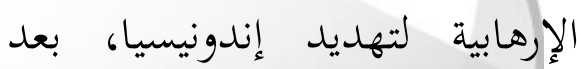

سنوات من المحاولات الفاشلة ويوجد

في إندونيسيا أكبر/دولة إسلامية

تعداداً بالسكان، حركة جهادية تعد

صغيرة مقارنة بحجم الدولة،

وأسهمت العديد من العوامل في منع

انتشار التطرف في هذا البلد، منها

الاستقرار، والحركة الديمقراطية، وقلة

الصراعات الداخلية، والجيران

المسالمون، والتسامح مع المدافعين

عن الشريعة الإسلامية، ويوجد فيها

أيضاً وحدة شرطية لمكافحة

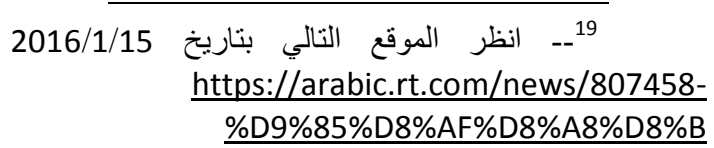


صدر عن ذلك القطاع الجهادي

المفكك، المستلهم من تنظيم داعش،

العديد من ادعائات القيادة من

جانب المتشددين مثل بكرون نعيم،

كرومسياه، وأبو جندل، وجميعهم

مقيمون في سوريا، أو تشيب

هيرناوان، 》الرئيس《 الذي نصب

نفسه على 》اداعش الأندونيسي."

على غرار ذذلك، يتضاءل عدد

القادمين من جنوب شرق آسيا إلى

العراق وسوريا عند مقارنته بعدد

المتطوعين من أوروبا وأستراليا. ويقدر

الباحث الأسترالي، جريج فيلي، أنه

مقابل كل مليون شخص في

أندونيسيا، قرر 1,4 رئ شيص

الانضمام إلى داعش. وفي ماليزيا،

يصل العدد إلى 8,5. بينما يصل

إلى 14 شخص لكل مليون

أسترالي، و18 لكل مليون فرنسي،

و40 لكل مليون بلجيكي. (21)

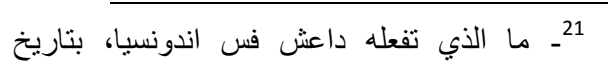

15فبر اير 2016 انظر الْوقع على الر ابط التالي
مستعلٌ لإنشاء فرع حقيقي للتنظيم.

ورغم أن داعش قد قطع بالفعل

شوطًا طويلًا في طريق اجتذاب

المتطوعين عبر الإنترنت، عمل

المسئولون الأمنيون الإقليميون

ومنظمات المختمع المددي بشكل

فعال لاستباق وصد الخطاب

الداعشي. علاوة على ذلك، يعتبر

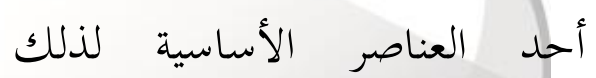

الخطاب - أي جاذبيته للمسلمين

المحرومين والمهمشين إجتماعيًا

واقتصاديًا - أقل جذبًا في جنوب

شرق آسيا عنه في أوروبا. يأتي معظم

داعمي داعش والمتعاطفين معه

داخل أندونيسيا من التنظيمات

الجهادية الموجودة بالفعل. حتى في

جنوبي الفلبين، حيث يبحث

المتشددون دومًا عن فكر لتبرير

ممارستهم للعنف، تعهد معظم

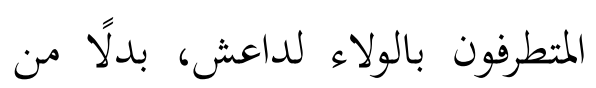

محاولة تشكيل تنظيم تابع له. وقد 
إن تنظيم داعش في اندونيسيا،

جدير بالذكر أن 392 إندونيسيا

مازال على شكل خلايا وبماعة

يقاتلون في الوقت الراهن في صفوف

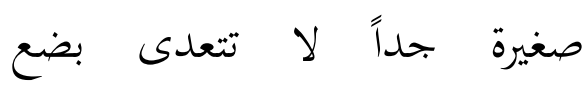

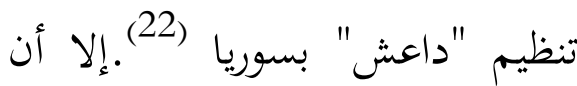

العشرات من الانصار، ولم ترتق ابداً

بعض التقارير الصحافية تقول إن

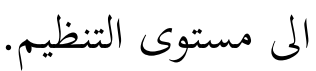

العدد تضاعف إلى 500 إندونيسي

إن هذه الخنايا واجبها تنفيذ

خلال عام 2015. يذكر أن معظم

عمليات انتحارية دموية، يمكن

العناصر التي انضمت لداعش في

تصنيفها في

سوريا هم من أفراد الجماعة

والاستقطاب ولا تمثل ابدًا أي ثقل

الإسلامية في جنوب شرق آسيا التي

لوجستي او تنظيمي في اندونيسيا.

نفذت تفجيرات بالي وعناصر من

بات واضحاً ان تنظيم داعش بدأ

تنظيم 》دار الإسلام《شفي إندونيسيا.

يتبع عمليات نوعية، اي تنفيذ

وظهرت جماعات صغيرة في

عمليات انتحارية على عرار

اندونيسيا تحت اسم 》التوحيد

تفجيرات باريس 3 نوفمبر 2015 في

وبماعة |(التوبة)《، قد اعلنت بيعتها

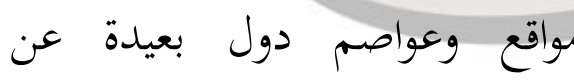

الى داعش، لكنها بمموعات صغيرة

معاقله بهدف تخفيف الضغوطات

لا تتعدى بضع عشرات من

عن معاقله وتعويض “"دعائي"

المؤيدين، ولم ترتقِ الى حجم التنظيم

اعلامي لخسارته في العراق وسوريا.

الناشطين

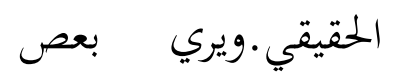

التنظيم الى تكرار هذه

والمحللين الاتي :

العمليات في عواصم دولية اخرى

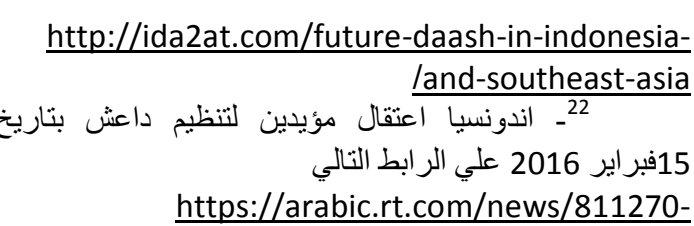

داعش: حقبقة التنظيم ة/أهد/ف 
بعيدة وقريبة من معاقله، ومنها والخطوات، سياسيا وماليا وميدانيا واجتماعيا ماليزية ودول جنوب شرق آسيا. وإعلاميا، وذلك على النحو التالي: هالتنيم لا يمثل تهديداً الى امن إهاء أي علاقة تربط أي دولة عربية اندونيسيا القومي في هذه المرحلة، بتظيم "داعش"، وإيقاف أي دعم

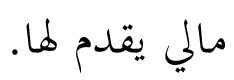
كون قدرته وقوته، لاتصل الى هذا - رفع الغطاء عن المخطط الأميركي الإسرائيلي البريطاني الذي عمل على صناعة "داعش" وتوظيفها لضرب الأمة عبر خطوات سياسية يتم التوافق عليها، بدءا بالتحذير اللفظي، مرورا بالشكوى الجادة لدى المحافل والمؤسسات الدولية، وصولا إلى فرضل إجراءات عقابية رادعة، فرديا وجماعيا. الحد، امام قدرة وكفاءة اجهزة الامن

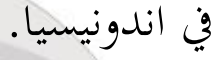
سوف تشهد دول جنوب شرق آسيا حالة من التأهب والاستنفار الامني، بدعم دولي، خاصة من استراليا في مواجهة خطر تنظيم داعش والجماعات الاخرى(23).

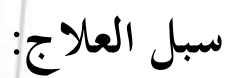
يري بعض المحللين والناشطين إن - عدم تقليم أي تسهيلات ميدانية من أي دولة عربية لعناصر التنظيم

$$
\text { هنا وهناك. }
$$

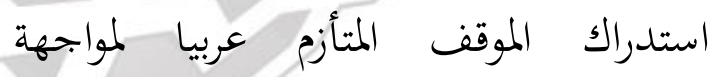

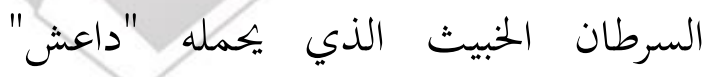
ويفتت أكباد الأمة يوما بعد يوم، يمتم العمل على ما يلي: - العيل

- - وقف أي مظهر من مظاهر التوظيف السلبي لأعمال وجرائم "داعش" لمش لعر على المستوى العربي الداخلي، ومبادرة الحكومات بخطوات لنزع

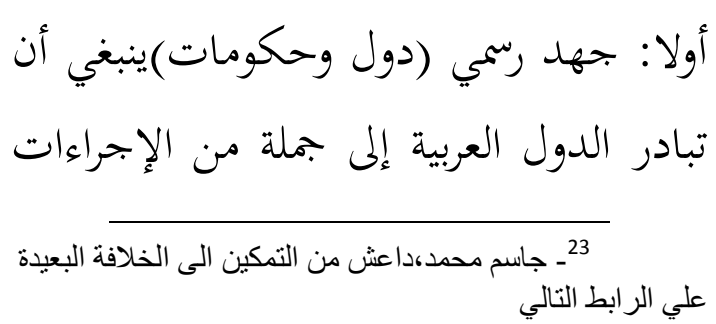
http://www.newsabah.com/wp/newspaper/716 
الاحتقان وتعزيز الثقة والأمان الخاتمة :

تحاول داعش الذراع الامريكي الصهيوني الانتشار في كل انحاء العالم بعد محاولاتما التغلغل وبناحها في الشرق الاوسط الذي تستغل عدم وجود انظمة للحكم فيه وتستغل الفوضي التي تجري فيه وهي تحاول الانتشار في اماكن بعيدة حتي تستطيع ان

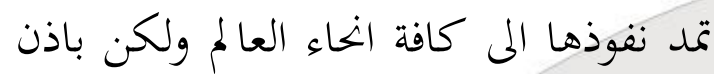

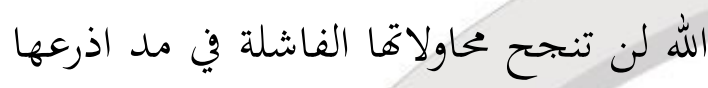

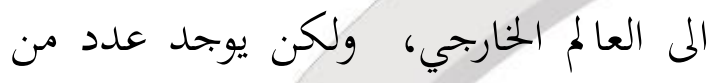

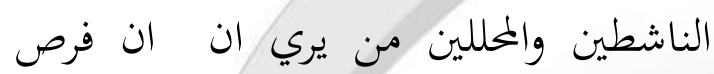
استمرار هذه 》الدولة| وتمددها أكثر من اي تنظيم آخر عرفته المنطقة، ومن غير المتوقع ان تختفي عن الخريطة السياسية بسهولة،

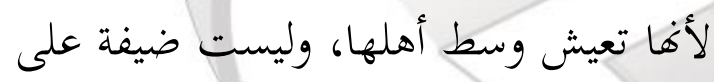

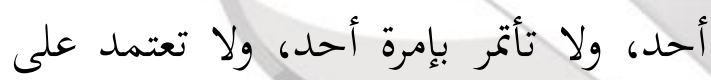

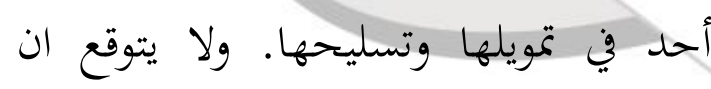
تؤدي الضربات الجوية الاميركية الى زوالها، لأغها بدأت تتأقلم مع هذه الضربات التي تزيد من شعبيتها في العالمين العربي والإسلامي، وتسهل عملية بتحنيد الآلاف من الشباب الإسلامي المحبط في صفوفها. ويخطئ من يظن أن 》الدولة الإسلامية《هي

http://www.aljazeera.net/home/print/6c87b8ad -70ec-47d5-b7c4-3aa56fb899e2/1977c76f-b6fe-

داعش: حقبقة التنظبم ة/الأ هداف
والاستقرار بين مكونات شعوبها

المختلفة.

ثانيا:

- - جهد حركي شعبي (قوى وتنظيمات

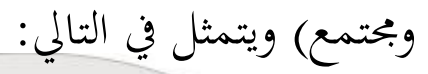

- توجيه إدانة جماعية صريحة من لدن كل القوى والتنظيمات والمؤسسات والشخصيات الإسلامية والوطنية والبحتمعية لجرائم "داعش"، والدعوة للتصدي له ومنع المزيد من تغوله

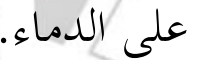

- امتناع القوى العلمانية عن استغلال جرائم "داعش" لتصفية حساباتما مع القوى الإسلامية.

- تسيير فعاليات جماعية منظمة في مختلف الأقطار العربية للتنديد بجرائم "داعش" وفضح المخطط الغربي الإسرائيلي الكامن وراء(24)

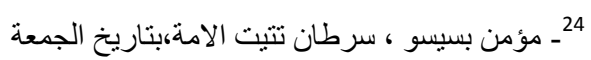
المو افق17ابريل 2015 موقع الجزيرة نت علي الر ابط النالي هنادى عبد الغني فضل السيد 
بحموعة قتلة ومغامرين، فهي تملك بنوك هناك أكثر من عشر دول إسلامية أخرى

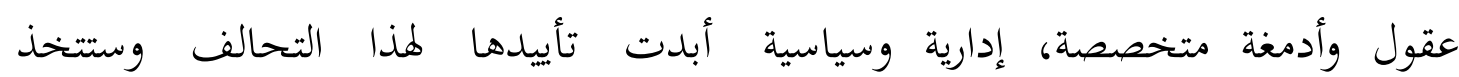

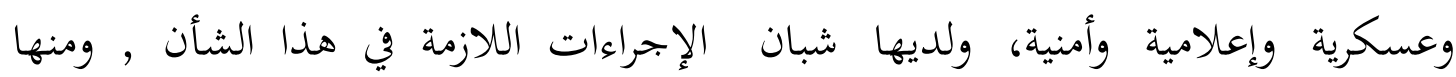

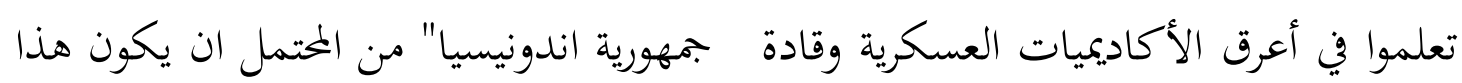

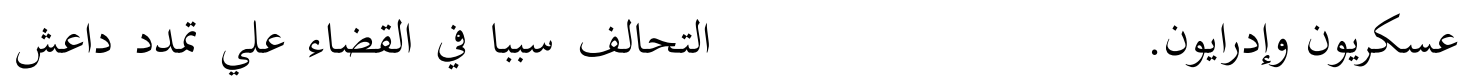

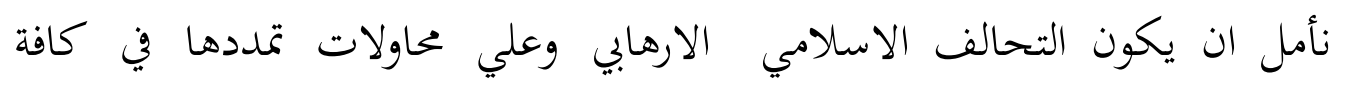

$$
\text { ويؤكد على مبادئ وأهداف ميثاق منظمة } 34 \text { دولة ومقره الرياض القطار العالم الاسلامي . }
$$

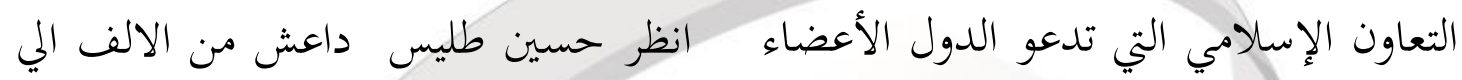

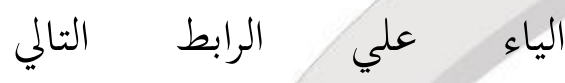

https://m.facebook.com/Dahhila/ انظر البلاد من هو تنظيم داعش علي الرابط

$$
\text { التالي }
$$

http://www.elbilad.net/flash/deta

إلى التعاون لمكافحة الإرهاب بجميع أشكاله

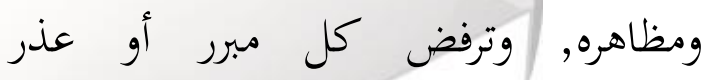
للإرهاب، فقد تقرر تشكيل تحالف عسكري

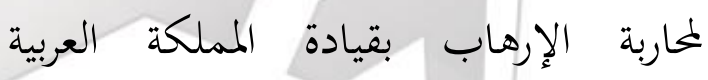
il?id=13052

لينا الخطيب،استرابتية تنظيم الدولة الاسلامية باقية وتتمدد،،بتاريخ 29يونيو علي رابط مركز كارينغي للشرق الاوسط علي الرابط التالي http://carnegiemec.org/publications/?fa=60542 انظر القدس العربي تنظين الدولة الاسلامية يرغم آلف السكان على مغادرة بلداتم شرق سوريا علي الرابط التالي http://www.alquds.co.uk/?p=189404

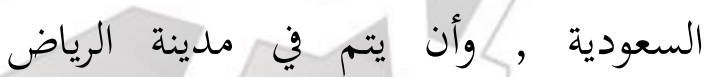
تأسيس مركز عمليات مشتركة لتنسيق ودعم العمليات العسكرية لمحاربة الإرهاب الدول المشاركة في التحالف إلى جانب السعودية هي: الأردن، الإمارات، باكستان، البحرين، بنغلاديش، بنين، تركيا، تشاد، توغو، تونس،

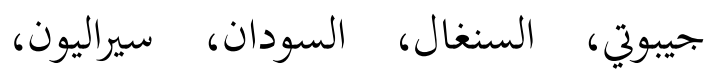
الصومال، الغابون، غينيا ، فلسطين، جزر القمر، قطر، ساحل العاج، الكويت، لبنان،

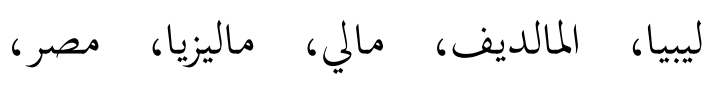
المغرب، موريتانيا، النيجر، نيجيريا، اليمن. 
http://www.alarab.co.uk/?id=283

$\underline{90}$

$$
\text { انطوان الحايك، ماوضات امريكية روسية قد }
$$

تنتج حربا منظمة علي داعش

واتباعها، بتاريخ 8تموز 2014 علي

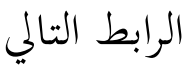

http://www.elnashra.com/news/show/76 $\underline{5412}$

$$
\text { انطوان الحايك مرجع سبق ذكرة }
$$

الحبيب علي الجفري داعية اسلامية معروف

kampung islam.org/isis-dan israel raya/pdf:11/02/20016 (5:2

تحليل ناصر الدويلة عضو البرلمان الكويتي

$$
\text { https://ar- انظر موقع }
$$

ar.facebook.com/MntdyAlatsam

Aldwy/posts/910389982382603

الجرديان تنشر خريطة انتشار داعش من

سوريا الي البوسنة ، بتاريخ الخميس

16 يوليو 2015علي الرابط التالي

http://elbadil.com/2015/07/16

انظر الموقعى التالي بتاريخ الثلاثاء، 22

$$
\text { ديسمبر } 2015
$$

http://s.youm7.com/2504902 http://www.youm7.com/s

انظر الموقع التالي بتاريخ 2016/01/15 http://www.alkhaleej.ae/alkhaleej Lpage/076581d8-6b5f-44f9-b3b9e38b9fecc351

$$
\text { انظر الموقع التالي بتاريخ 2016/1/15 }
$$

https://arabic.rt.com/news/8074

$\% \mathrm{D} 9 \% 85 \% \mathrm{D} 8 \% \mathrm{AF} \% \mathrm{D} 8 \% \mathrm{~A} \frac{58-}{8 \%}$

D $8 \% \mathrm{~B}$

$$
\text { ميادة ابو طالب الارهاب في قلب اروربا، }
$$

$$
\text { بتاريخ الاربعاء } 17 \text { فبراير 2016علي }
$$

$$
\text { الرابط التالي }
$$

http://www.elmogaz.com/node/2

$\underline{67811}$

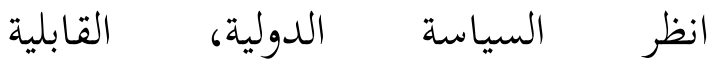

للاحتضان:عوامل صعود السلية

الجهادية في بلاد الشام، علي

الرابط التالي

http://www.siyassa.org.eg/UI/Front/Inner Print.aspx?NewsContentID $=378$

$$
\text { لينا الخطيب، مرجع سبق ذكره }
$$

ماثيو ليفنت وريان ليوكيليس ، النتائج

المستخلصة من تحليل وزارة الخارجية

الامريكية عن الارهاب الجزء الثاني

"تنامي تنظيم الدولة الاسلامية كرية 6

معهد واشنطن، بتاريخ 19 يونيو

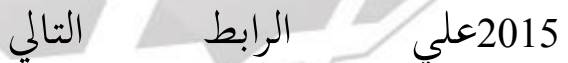

http://www.washingtoninstitute.

org

المحامي سفيان الشوا ، داعش من اين والي

اين الدستور بتاريخ 6يوليو 2014

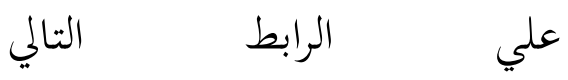

. lhttp://www.addustour.com

تركي الحمد صحيفة العرب، بتاريخ 24فبراير 2016العدد 10195 علي الرابط

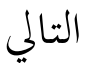

